\title{
Causes of death in hospitalized children younger than 12 years of age in a Chinese hospital: a 10 year study
}

\author{
Yueniu Zhu, Xiaodong Zhu*, Mengyan Deng, Hongxia Wei and Mingjun Zhang
}

\begin{abstract}
Background: In China, the majority (77\%) of urban children die in hospitals. Hospital-based review could provide insight leading to improvements in clinical practice and increase the survival of critically ill children. The aim of the present study is to identify the trends of immediate causes and chronic underlying diseases associated with deaths of children at one of the largest teaching hospitals in China over a period of 10 years (2006-2015).

Methods: A retrospective analysis of data of all children aged 1 month to 11 years who died at Xinhua Hospital between 2006 and 2015. Demographic details, main causes of deaths, and chronic underlying diseases were reviewed.

Results: Case fatality rate was $0.55 \%(510 / 93,443)$ and it represented $0.41-0.80 \%$ deaths per year. Overall, the most common immediate causes of deaths in hospitalized children were pneumonia (36.7\%), sepsis (13.5\%), tumour (11.4\%), followed by nontraumatic intracranial or gastrointestinal hemorrhage (10.6\%) and cardiac shock (9.6\%). Over $70 \%$ of the deaths in children were complicated with chronic underlying diseases. Congenital abnormality was the most frequent chronic underlying disease observed in infants (60.3\%) and tumour was the main chronic underlying disease in toddlers (31.1\%) and older children (44\%).

Conclusions: Infectious diseases, especially pneumonia, were the major immediate causes of deaths, and the mortality in the study population decreased with age. Tumour and other noninfectious disease accounted for more deaths in older children. Chronic underlying diseases were found in most deaths of children.
\end{abstract}

Keywords: Cause of death, Chronic disease, Congenital abnormality, Hospitalized children, Infectious diseases, Pneumonia

\section{Background}

Mortality rate in children is decreasing worldwide. Mortality in children younger than 5 years has dropped from 11.9 million in 1990 to 7.7 million deaths in 2010 [1]. Official data from the United Nations indicated that China made progress in the significant reduction of neonatal, infant, and childhood deaths during the past few decades [2, 3]. Expecting to achieve the Millennium Development Goal 4, global and local assessments of mortality in newborn and children younger than 5 years are well implemented. However, these estimations do not provide enough information for the identification of

\footnotetext{
* Correspondence: zhuxiaodong@xinhuamed.com.cn

Department of Pediatric Critical Care Medicine, Xinhua Hospital affiliated to Shanghai Jiaotong University School of Medicine, Shanghai 200092, China
}

the complex causes of deaths in children such as different age groups, immediate cause of death, and chronic underlying diseases contributing to death. The spectrum and characteristics of diseases shift gradually with the growth and development of children. Further investigations on these complex causes of deaths in children could give more information to the healthcare providers to recognize fatal situations. A comprehensive understanding of the causes of death could help improve high quality of hospital care for children and would promote better outcomes.

In China, the majority (77\%) of urban children die in hospitals [4]. The number of children hospitalized is increasing, especially in urban centers and large community hospitals. Improving hospital care for seriously ill 
children is critical for promoting children's health. Although hospital-based mortality review may not be a whole reflection of deaths from various causes in the general population, it may provide opportunities to examine the immediate and underlying causes contributing to deaths occurring at health facilities. With in-depth investigations, these assessments could forewarn the high-risk patient and renew the sense of commitment to fatal conditions among healthcare staff. The World Health Organization describe hospital-based review as one of the main types of death review that has the potential to provide great improvements in clinical practice and increase the survival of critically ill children [5].

To improve the understanding of the causes of death in children and provide clinical cautionary information to professional healthcare providers, the present study aimed to retrospectively review and identify the trends of immediate causes and chronic underlying diseases associated with deaths of children at one of the largest tertiary-level hospitals in China.

\section{Methods}

Study design

This retrospective study was carried out to examine the causes of death of paediatric patients who died at the studied hospital. Clinical data of a 10-year period (20062015) was collected and examined for children aged 1 month-11 years who died during the study period. This hospital under discussion was the first institution which set up subspecialty departments for children in China. It is the largest general hospital serving as a medical center for local children in Shanghai and also as a tertiary referral centre for children with complex paediatric conditions in the east of China. Each year there are about 10,000 children discharged from the hospital.

The study protocol was approved by the Ethics Committees of the studied hospital, and the need for written informed consent was waived by the committee as all data were used retrospectively and de-identified.

\section{Data collection and management}

Data used in this study were drawn from the hospital information services department databases. These databases prospectively recorded demographic and clinical data on all hospitalized children. The children who died in the emergency department were not included due to incomplete medical records. Demographic details, main causes of deaths, chronic underlying diseases, and other diagnoses during the hospitalization according to the International statistical classification of diseases and related health problems - 10th revision were studied. The main cause of death in the present study referred to the diagnosis of direct cause of death registered on the death certificate, and the chronic underlying diseases referred to the complicated chronic disease diagnosed before death. The medical records of every dead cases were reviewed to confirm the diagnosis on the death certificate. In the study, the direct causes of death were further divided into infectious and noninfectious diseases. The main category of chronic underlying diseases was defined as congenital abnormalities, immunodeficiency and autoimmune diseases, tumours, and others (e.g. malnutrition, obesity, hemophilia, et al.). After reviewing the medical history of the tumour cases, we classify the direct causes of death into tumour while death was caused by the tumour compression or metastasis and complications after aggressive treatment (such as infection or hemorrhage) [Additional file 1]. Clinical data was also divided into three groups by age: 1-12 months old (infants), 1-4 years old (toddlers), and 5-11 years old (older children).

\section{Statistic analysis}

Percentage and proportional mortality ratios were calculated using Microsoft Excel software. Statistical analyses were performed using GraphPad Prism 7.0 for Mac OS X. Data was expressed as mean \pm standard deviation (SD). Differences between proportions of groups were analyzed for statistical significance using the chi-square test. The level of statistical significance was set at $p<0.05$.

\section{Results}

During the study period, 93,443 children were hospitalized; of whom, $510(0.55 \%)$ died. The annual overall fatality rate varied from $0.41 \%$ to $0.8 \%$. The majority of deaths in the study occurred in children under 5 years of age (77\%) including $42 \%$ in infants. Children aged 5-11 years accounted for $23 \%$ of the deaths in this study (Table 1).

Overall, the most common causes of deaths in the hospitalized children were pneumonia (36.7\%), sepsis (13.5\%) and tumour (11.4\%), and followed by nontraumatic intracranial or gastrointestinal hemorrhage (10.6\%), cardiac shock (9.6\%), central nerve system infection (7.6\%), accident (6.1\%), and diarrhoea (3.1\%, Table 1$)$.

\section{Distribution of immediate cause of death}

The main causes of deaths based on the ages are shown in Table 2. Infectious diseases caused the majority of the deaths in children under 5 year age. The overall deaths caused by infectious diseases decreased significantly with age, from $72.4 \%$ in infants to $44.8 \%$ in elder children $(p<0.0001)$. Of all the infectious diseases, pneumonia, sepsis, and CNS infection were the main causes of death throughout childhood. The proportion of deaths from 
Table 1 Characteristic of children died in Xinhua Hospital during 2006-2015

\begin{tabular}{ll}
\hline Characteristic & Value \\
\hline Age, mean (range) & 34 mo (1-144mo) \\
Infants, No. (\%) & $214(42)$ \\
Toddler, No. (\%) & $180(35.3)$ \\
Older children, No. (\%) & $116(22.7)$ \\
Gender, No. (\%) & \\
Male & $308(60.4)$ \\
Female & $202(39.6)$ \\
Immediate cause of death, No. (\%) & \\
Infectious diseases & $311(60.9)$ \\
Pneumonia & $187(36.7)$ \\
Sepsis & $69(13.5)$ \\
CNS infection & $39(7.6)$ \\
Diarrhoea & $16(3.1)$ \\
Non infectious diseases & $192(37.7)$ \\
Non traumatic intracranial/ & $54(10.6)$ \\
gastrointestinal hemorrhage & \\
Cardiac shock & \\
Tumour & \\
Accident & \\
Other & \\
With chronic underlying diseases, & \\
No. (\%) & $54(125(24.6)$ \\
Congenital abnormalities & $31(6.1)$ \\
Immunodeficiency and Autoimmune \\
diseases
\end{tabular}

pneumonia also decreased with this reduction, from $51.4 \%$ in infants to $20.7 \%$ in older children $(p<0.0001)$. On the contrary, the overall death due to noninfectious disease increased significantly with age. Of all these noninfectious diseases, non-traumatic intracranial or gastrointestinal hemorrhage, cardiac shock, tumour, and accident were the main causes of death. The proportion of deaths from tumour and accidents increased dramatically with age.

In infants, pneumonia caused the largest proportion of deaths (51.4\%), while sepsis and cardiac shock were the second and third main causes. In toddlers pneumonia was also the leading cause of death, while sepsis and tumours contributed substantially. In older children, despite the proportion of pneumonia deaths decreasing to $20.7 \%$, it remained a main cause of death, followed by tumour, non-traumatic intracranial or gastrointestinal hemorrhage, and sepsis (Table 2).

\section{Underlying chronic disease related to death}

Between 74.1 and $79.9 \%$ of the deaths in children were complicated with chronic underlying diseases (Table 3). A congenital abnormality was the most frequent chronic underlying disease observed in infants, and this proportion decreased dramatically with age. Of the deaths in infants, $60.3 \%$ were complicated with congenital abnormalities, while the proportion decreased to $31.1 \%$ in toddlers and $17.2 \%$ in older children $(p<0.0001)$. Congenital abnormalities of the heart and the nervous system were the main abnormalities found in the deaths of children (Fig. 1). The main direct causes of death in the children with congenital abnormalities were infectious diseases $(n=153,74.6 \%)$, while the other children with congenital abnormalities died from organ dysfunction due to the abnormalities.

Table 2 Cause of death distribution by age in children at Xinhua Hospital during 2006-2015

\begin{tabular}{|c|c|c|c|c|c|c|c|}
\hline & \multicolumn{2}{|c|}{ Infants $(n / 214)$} & \multicolumn{2}{|c|}{ Toddlers $(n / 180)$} & \multicolumn{2}{|c|}{ Older children $(n / 116)$} & \multirow[t]{2}{*}{$p$ value $e^{a}$} \\
\hline & $\mathrm{n}$ & $\%$ & $\mathrm{n}$ & $\%$ & $\mathrm{n}$ & $\%$ & \\
\hline Infectious diseases & 155 & 72.4 & 104 & 57.7 & 52 & 44.8 & $<0.0001$ \\
\hline Pneumonia & 110 & 51.4 & 53 & 29.4 & 24 & 20.7 & $<0.0001$ \\
\hline Sepsis & 25 & 11.7 & 29 & 16.1 & 15 & 12.9 & 0.4306 \\
\hline CNS infection & 11 & 5.1 & 17 & 9.4 & 11 & 9.5 & 0.1939 \\
\hline Diarrhoea & 9 & 4.2 & 5 & 2.8 & 2 & 1.7 & 0.4399 \\
\hline Non infectious diseases & 56 & 26.2 & 73 & 40.6 & 63 & 54.3 & $<0.0001$ \\
\hline $\begin{array}{l}\text { Non traumatic intracranial/ } \\
\text { gastrointestinal hemorrhage }\end{array}$ & 17 & 8.0 & 21 & 11.7 & 16 & 13.8 & 0.2165 \\
\hline Cardiac shock & 24 & 11.2 & 14 & 7.8 & 11 & 9.5 & 0.5136 \\
\hline Tumour & 8 & 3.7 & 24 & 13.3 & 26 & 22.4 & $<0.0001$ \\
\hline Accident & 7 & 3.3 & 14 & 7.8 & 10 & 8.6 & 0.0751 \\
\hline Other & 3 & 1.4 & 3 & 1.7 & 1 & 0.9 & 0.8438 \\
\hline
\end{tabular}

${ }^{\mathrm{a} C h i-s q u a r e d ~ t e s t ~}$ 
Table 3 Distribution of chronic underlying diseases of children who died in Xinhua Hospital during 2006-2015

\begin{tabular}{|c|c|c|c|c|c|c|c|}
\hline & \multicolumn{2}{|c|}{ Infants $(n / 214)$} & \multicolumn{2}{|c|}{ Toddler $(n / 180)$} & \multicolumn{2}{|c|}{ Older children $(n / 116)$} & \multirow[t]{2}{*}{$p$ value $^{a}$} \\
\hline & $n$ & $\%$ & $\mathrm{n}$ & $\%$ & $n$ & $\%$ & \\
\hline With chronic underlying diseases & 171 & 79.9 & 134 & 74.4 & 86 & 74.1 & 0.3384 \\
\hline Congenital abnormalities & 129 & 60.3 & 56 & 31.1 & 20 & 17.2 & $<0.0001$ \\
\hline Immunodeficiency and Autoimmune diseases & 18 & 8.4 & 22 & 12.2 & 14 & 12.0 & 0.3970 \\
\hline Tumour & 18 & 8.4 & 56 & 31.1 & 51 & 44.0 & $<0.0001$ \\
\hline Other & 6 & 2.8 & 0 & 0 & 1 & 0.9 & 0.0506 \\
\hline Without chronic underlying diseases & 43 & 20.1 & 46 & 25.6 & 30 & 25.9 & 0.3384 \\
\hline
\end{tabular}

${ }^{a}$ Chi-squared test

On the other hand, a tumour was the main chronic underlying disease in the children that died at more than 1 year of age and the proportion increased with age. Only $8.4 \%$ of the deaths in the infant group were complicated with a tumour, while the proportion increased significantly to $31.1 \%$ in toddlers and $44 \%$ in older children $(p<0.0001)$. The main direct cause of death in children with a tumour was therapy relatedcomplications $(n=68,54.4 \%)$, while the rest died from organ dysfunction due to tumour compression or metastasis. The therapy related-complications included serious infection $(n=45,36 \%)$ and hemorrhage $(n=23,18.4 \%)$.

\section{Discussion}

The current study aimed to identify the main causes and complications underlying diseases associated with deaths in children. Children hospitalized at a tertiary hospital represent the important subgroups to have high risk of mortality. Reviewing hospital deaths in a structured way could provide good understanding of causes of deaths and allow improving of better interventions.

In the present study, $77 \%$ of deaths occurred in children under the age of five including $42 \%$ in children under 1 year of age. This is similar to the studies that mentioned around $80 \%$ of deaths occurred in children who were under 5 years in hospitals of developing countries $[6,7]$, and infant mortality accounting for $30-50 \%$ of all deaths among children younger than 5 years of age in Asia [8,9] These data suggest the vulnerability of children in these ages. The number of dead case in boys is a bit more than that in girls. This might partially due to the Chinese tradition of preference boys to girls while more seriously ill boys were transferred to the senior medical center.

\section{Cause of death in hospitalized children}

The study results showed that infectious diseases, accounting for $61 \%$ of total death, were the leading causes of death in children under 5 years age. The infectious disease category in the study included pneumonia, sepsis, CNS infection, and diarrhoea. The proportion of infectious diseases and pneumonia decreased significantly with age. These trends were similar to that described globally and regionally $[10,11]$. These shifts may associate with gradual maturity of children's immune system and also benefit from increased immunization procedures introduced to older children (A serial of vaccinations are compulsory or recommended to children from birth to 8 years. The compulsory vaccines include Bacillus Calmette-Guerin, Hepatitis B, poliomyelitis, diphtheria/pertussis/Tetanus, measles, Japanese encephalitis, epidemic encephalitis, et al.).

Pneumonia is the leading infectious causes of childhood morbidity and mortality worldwide [1, 12]. With an estimated 146-159 million new episodes per year in developing countries, pneumonia is estimated to cause

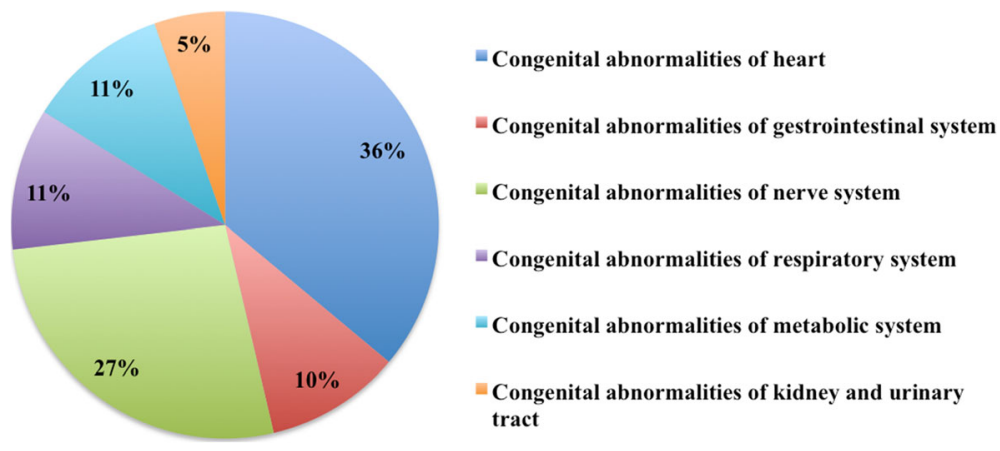

Fig. 1 Distribution of congenital diseases in children who died at Xinhua Hospital during 2006-2015 
approximately 2 million deaths among children globally [13]. In China, pneumonia is also the most frequent cause of deaths in children [14]. In the present study, pneumonia was, as expected, the 'top killer' of children. The study suggested that younger children and children with chronic underlying diseases (particularly congenital diseases) were more likely to die from pneumonia. It has been proved that different organisms could be isolated from these susceptible children [15]. In infants, pneumonia mostly results from respiratory viruses and bacterial etiologies such as Streptococcus pneumonia. Children with chronic disease often acquire pneumonia caused by Klebsiella, Enterobacter, Pseudomonas, and Acinetobacter [15]. Results of a global study suggested that several preventive and therapeutic strategies such as appropriate antibiotics, vaccination, and preventive zinc supplementation were effective in the control of pneumonia [16]. This simulation also estimated that $51 \%$ of pneumonia deaths would be saved by 2025 if targeted strategies are implemented at present.

Although diarrhoea was described as a leading cause of death in children globally $[1,10]$, diarrhoea was not a common cause of child deaths in all age groups (only $1.7-4.2 \%)$ in this study. The distribution is consistent with the national mortality report $[11,14]$. The lower Chinese mortality contrasted to the global results might relate the common cultural practice of boiling water, introduction of rotavirus vaccine, and other hygiene practices in China.

\section{Chronic underlying disease related to death}

The present study found that more than $70 \%$ of the deaths in children were complicated with chronic underlying diseases. The number of morbidity of chronic disease in the study is far more prevalent than that in the general population which is varied from $1.5-5 \%[11,17]$. This suggested that children with complex chronic conditions were a small subset of children that accounted for more than half of childhood death from medical causes. It was estimated that around $70 \%$ of no injury deaths among children ages 1-4 and and more than $80 \%$ of deaths among all school-age children were result of chronic causes [18]. These data were similar with the present study results, and this suggests that chronic underlying disease may play an important role in the death of children.

This study found that congenital abnormality was the most frequent chronic underlying disease observed in children under 1 year of age, and the proportion decreased dramatically with increase in age. Tumours became the leading chronic underlying disease in children aged 5-11 years, followed by congenital abnormalities and immune diseases. Even with advances in corrective surgery, congenital heart disease remains the leading cause of death in children with congenital malformations [15]. In the present study, congenital heart disease attributed $36.1 \%$ in all congenital abnormalities. Acute infectious disease is an important cause of death in children with chronic illness in the developed countries [19]. In the study, about three quarters of the congenital abnormality children died from infectious disease, and rest of the population died from organ decompensate due to congenital abnormality. The trends indicated that children complicated with congenital abnormalities are on the risk of life-threatening infection and require specialized care to prevent early deaths. The hospital medical staff needs to be alerted to the signs or symptoms which might be relevant to infection in these children.

Tumours remain a major cause of death in children $[11,20]$, although outcomes have considerably improved over the past few decades (five-year survival increasing from approximately $40 \%$ in the 1970 s to approximately $80 \%$ in the 2000 s $[21,22]$ ). The morbidity and mortality of a tumour also increases with age [11]. In the present study, up to $44 \%$ of the deaths of children in 5-11 years group were related to a tumour. As the development of oncotherapy and do-not-attempt-resuscitation orders remain uncommon in paediatric practice, more children with tumours die in the hospital [23, 24]. It was reported that the main causes of death in hospitalized children with a tumour were severe sepsis, pneumonia, and respiratory failure $[25,26]$. The present study indicated that at least $54.4 \%$ of deaths in these children were due to complications from oncotherapy. These complications included serious infection (36\%) and hemorrhage (18.4\%). Several strategies such as admission to palliative intensive care unit, providing organ support and early aggressive hemodynamic assessment were proved to be effective in patients at risk of these life-threatening complications [27, 28]. Careful observation and early intervention of these patients could increase the survival and make them benefit more from the advances in oncotherapy.

The relationship between chronic underlying diseases and deaths has, to our knowledge, not been mentioned much in previous death reviews. The present study indicated that most children died with chronic underlying diseases. Congenital abnormalities were the major chronic underlying disease in infants and a tumour was the main chronic disease in children more than 1 year of age. Infection diseases and therapy related-complications were often life-threatening in these children. Thus, this study may help to highlight the improvement of clinical evaluation and management in these children with complex clinical condition.

\section{Limitation}

The major limitation of this study was its retrospective design. Although some parts of the results were 
consistent with the global and national data of mortality, these results should be interpreted bearing in mind that they only included deaths occurring at a tertiary health care facility. This study discussed the main diseases related to the death of children. Further investigation should be carried out to explore the clinical presentation and therapy strategies related to death in hospitalized children. With this information, healthcare providers could recognize fatal situation more efficiently and treat these patients more effectively.

\section{Conclusion}

Infectious diseases, especially pneumonia and sepsis, were the major immediate causes of death, and the mortality decreased with age in children more than 1 year of age. In contrast, a tumour and accident accounted for more deaths in children more than one-year of age. Chronic underlying diseases were found in most deaths of children. Congenital abnormalities were the major chronic underlying disease in infants and a tumour was the main chronic disease in children more than 1 year of age. Infection diseases and therapy-related complications were often lifethreatening in these children.

\section{Additional file}

Additional file 1: Disease category. (DOC $36 \mathrm{~kb}$ )

\section{Acknowledgements}

Not applicable.

\section{Funding}

There is no funding for the study.

\section{Availability of data and materials}

The data that support the findings of this study are available from Xinhua Hospital affiliated to Shanghai Jiaotong University School of Medicine, but restrictions apply to the availability of these data, which were used under license for the current study, and so are not publicly available. Data are however available from the authors upon reasonable request and with permission of Xinhua Hospital.

\section{Author's contributions}

$Y Z$ designed the study, analyzed the patient data and write the manuscript. $X Z$ designed and interpreted the results. MD, HW collected the data from the database of the hospital. MZ checked the data. All authors read and approved the final manuscript.

\section{Ethics approval and consent to participate}

The study protocol was approved by the Ethics Committees of the studied hospital, and the need for written informed consent was waived by the committee as all data were used retrospectively and de-identified. The consent to participate is not applicable.

\section{Consent for publication}

Not applicable.

\section{Competing interests}

The authors declare that they have no competing interests.

\section{Publisher's Note}

Springer Nature remains neutral with regard to jurisdictional claims in published maps and institutional affiliations.

Received: 17 September 2016 Accepted: 29 December 2017

Published online: 18 January 2018

\section{References}

1. Liu L, Johnson HL, Cousens S, Perin J, Scott S, Lawn JE, et al. Global, regional, and national causes of child mortality: an updated systematic analysis for 2010 with time trends since 2000. Lancet. 2012;379(9832):2151-61.

2. Rajaratnam JK, Marcus JR, Flaxman AD, Wang H, Levin-Rector A, Dwyer L, et al. Neonatal, postneonatal, childhood, and under-5 mortality for 187 countries, 1970-2010: a systematic analysis of progress towards millennium development goal 4. Lancet. 2010;375(9730):1988-2008.

3. Wang $H$, Liddell CA, Coates MM, Mooney MD, Levitz CE, Schumacher AE, et al. Global, regional, and national levels of neonatal, infant, and under-5 mortality during 1990-2013: a systematic analysis for the global burden of disease study 2013. Lancet. 2014;384(9947):957-79.

4. China Institute for Reform and Development China Human Development Report 2007/08. Access for all: Basic public services for 1.3 billion people. China Translation and Publishing Corporation, China: p121-122.

5. Theiss-Nyland K, Rechel B. PMNCH Knowledge Summary 2013\#27, Death review: maternal, prenatal and child. 2013. http://www.who.int/pmnch/ knowledge/publications/summaries/ks27.pdf. Accessed 5 Jan 2015.

6. George IO, Alex-Hart BA, Frank-Briggs Al. Mortality pattern in children: a hospital based study in Nigeria. Int J Biomed Sci. 2009;5(4):369-72.

7. Celine T. A study on childhood death at a tertiary care level in ernakulam district. Ann Med Health Sci Res. 2013;3(3):407-11.

8. Lozano R, Wang H, Foreman KJ, Rajaratnam JK, Naghavi M, Marcus JR, et al. Progress towards millennium development goals 4 and 5 on maternal and child mortality: an updated systematic analysis. Lancet. 2011;378(9797):1139-65.

9. United Nations Inter-agency Group for Child Mortality Estimation. Levels and trends in child mortality. Report 2015. http://data.unicef.org/wpcontent/uploads/2015/12/IGME-report-2015-child-mortality-final_236.pdf. Accessed 14 Jan 2018.

10. Lozano R, Naghavi M, Foreman K, Lim S, Shibuya K, Aboyans V, et al. Global and regional mortality from 235 causes of death for 20 age groups in 1990 and 2010: a systematic analysis for the global burden of disease study 2010. Lancet. 2012;380(9859):2095-128.

11. National health and family planning commission of China. Chinese Health Statistics Yearbook 2013. 2013. http://www.nhfpc.gov.cn/htmlfiles/zwgkzt/ ptjnj/year2013/index2013. Accessed 5 Jan 2015.

12. Bucens IK, Reid A, Barreto AC, Dwivedi V, Counahan M. Three years of paediatric morbidity and mortality at the National Hospital in Dili, East Timor. J Paediatr Child Health. 2013:49(12):1004-9.

13. Wardlaw T, Salama P, Johansson EW, Mason E. Pneumonia: the leading killer of children. Lancet. 2006:368(9541):1048-50.

14. Rudan I, Chan KY, Zhang JS, Theodoratou E, Feng XL, Salomon JA, et al. Causes of deaths in children younger than 5 years in China in 2008. Lancet. 2010;375(9720):1083-9.

15. Perkin RM, Swift JD, Newton DA, Anas NG. Pediatric hospital medicine. 2nd ed. USA: Lippincott Williams \& Wikins; 2008. p. 434-6.

16. Bhutta ZA, Das JK, Walker N, Rizvi A, Campbell H, Rudan I, et al. Interventions to address deaths from childhood pneumonia and diarrhoea equitably: what works and at what cost? Lancet. 2013;381(9875):1417-29.

17. Newacheck PW, Strickland B, Shonkoff JP, Perrin JM, McPherson M, McManus M, et al. An epidemiologic profile of children with special health care needs. Pediatrics. 1998;102(1):117-23.

18. Wise PH. The transformation of child health in the United States. Health Aff (Millwood). 2004;23(5):9-25.

19. Elixhauser A, Machlin SR, Zodet MW, Chevarley FM, Patel N, McCormick MC, et al. Health care for children and youth in the United States: 2001 annual report on access, utilization, quality, and expenditures. Ambul Pediatr. 2002;2(6):419-37.

20. Bleyer WA. The U.S. pediatric cancer clinical trials programmes: international implications and the way forward. Eur J Cancer. 1997;33(9):1439-47.

21. Steliarova-Foucher E, Stiller C, Kaatsch P, Berrino F, Coebergh JW, Lacour B, et al. Geographical patterns and time trends of cancer incidence and survival among children and adolescents in Europe since the 1970s (the ACCISproject): an epidemiological study. Lancet. 2004;364(9451):2097-105. 
22. Yang L, Fujimoto J. Childhood cancer mortality in Japan, 1980-2013. BioMed Central Cancer. 2015;15:446.

23. Ramnarayan $\mathrm{P}$, Craig F, Petros $A$, Pierce C. Characteristics of deaths occurring in hospitalised children: changing trends. J Med Ethics. 2007;33(5):255-60

24. Yanai T, Hirase S, Matsunoshita N, Yamamoto N, Ninchoji T, Kubokawa I, et al. Place of death of pediatric cancer patients in a single institute during 7 years. Kobe J Med Sci. 2012;58(2):E33-40.

25. Villa F, Coppadoro A, Bellani G, Foti G, Fumagalli R, Pesenti A. Etiology of respiratory failure is related to mortality in critically ill patients affected by a hematological malignancy: a retrospective study. Minerva Anestesiol. 2010;76(1):7-12.

26. Demaret $P$, Pettersen $G$, Hubert $P$, Teira $P$, Emeriaud $G$. The critically-ill pediatric hemato-oncology patient: epidemiology, management, and strategy of transfer to the pediatric intensive care unit. Ann Intensive Care. 2012;2(1):14.

27. Gow KW, Heiss KF, Wulkan ML, Katzenstein HM, Rosenberg ES, Heard ML, et al. Extracorporeal life support for support of children with malignancy and respiratory or cardiac failure: the extracorporeal life support experience. Crit Care Med. 2009;37(4):1308-16.

28. Azoulay E, Soares M, Darmon M, Benoit D, Pastores S, Afessa B. Intensive care of the cancer patient: recent achievements and remaining challenges. Ann Intensive Care. 2011;1(1):5.

Submit your next manuscript to BioMed Central and we will help you at every step:

- We accept pre-submission inquiries

- Our selector tool helps you to find the most relevant journal

- We provide round the clock customer support

- Convenient online submission

- Thorough peer review

- Inclusion in PubMed and all major indexing services

- Maximum visibility for your research

Submit your manuscript at www.biomedcentral.com/submit
C) Biomed Central 